\title{
REGULATION IN COLLABORATIVE PROJECT-BASED DESIGN EDUCATION: AN INTERVENTION STUDY MEASURING THE EFFECTIVENESS OF A GROUP AWARENESS TOOL
}

\author{
Lore BROSENS ${ }^{1,2}$, Johanna Renny OCTAVIA ${ }^{1,3}$, Annelies RAES ${ }^{4,5}$ and Marina \\ EMMANOUIL ${ }^{1,2}$ \\ ${ }^{1}$ Ghent University, Dept. of Industrial Systems Engineering and Product Design, Belgium \\ ${ }^{2}$ Ghent University, Design. Nexus, Belgium \\ ${ }^{3}$ imec-mict-UGent, De Krook, Belgium \\ ${ }^{4}$ ITEC, imec research group at KU Leuven, Belgium \\ ${ }^{5} \mathrm{KU}$ Leuven Kulak, Faculty of Psychology and Educational Sciences, Belgium
}

\begin{abstract}
The fourth industrial revolution is on the horizon and many design engineering jobs of the future are largely unidentified. Tomorrow's product designers must be able to deal with cutting-edge technology, big data and most importantly to collaborate and react resiliently to changes in the Knowledge Age. Contemporary discourse urges a shift towards multidisciplinary teams in which students must be trained to move from individual to collaborative problem-solving practices. This study examines whether the implementation of a group awareness (GA) tool in a third-year bachelor industrial design engineering course can have a positive impact on learning and teamwork dynamics. The participants of the study (n $=33$ ) were encouraged to take part in group regulating exercises. Students were asked to self-assess the current state of collaboration via a mandatory GA survey, scoring their participation in the group work. After being informed of these results, students were asked to reflect and pose possible behavioural changes on an individual- and group-level. In addition, students received suggestions on how to collaborate through a mandatory scripted peer critique session in which they identified issues, talked about design decisions and created a common ground for further action. The results of the study indicated that the use of the GA tool enabled students to reflect on the different perspectives team members bring to the group's project. This paper discusses the possibilities and shortcomings of implementing a group awareness tool in design engineering education and further research on this topic.
\end{abstract}

Keywords: Engineering design education, self-regulation (SR), group awareness (GA), collaborative learning, project-based learning

\section{INTRODUCTION}

Given the rapid contemporary technological changes in Industry 4.0, it becomes clear that design curricula need to adapt [1], [2]. The recent industrial changes enable trends such as additive manufacturing and mass customization to become fully developed topics. However, the main driver behind the possibility to develop, for example, 3D print personalised goods, is the generation of big data and knowledge transfer. Moreover, the emerging Knowledge Age brings along a higher complexity [2], for instance, the jobs in which design engineers will work by 2030 are loosely defined [3]. This uncertainty challenges design curricula as it becomes clear that future design engineers will need to be prepared to work within a digital Industry 4.0. Yet, due to the ever-changing character of these technologies, it seems unclear what skills need to be taught in higher education institutions.

It has been argued that the acquisition of "soft skills" could prepare students to adapt to Industry 4.0's requirements [4]. These soft skills that are often referred now as $21^{\text {st }}$ Century skills, include project planning, critical thinking, collaborative problem solving and communication skills [5]. It is notable that these skills (as most design skills) cannot be taught in a traditional way because the knowledge transfer process related to these skills is tacit; it is acquired in practice [6]. The acquisition of tacit knowledge is a challenge most engineering design curricula address by using constructivist learning approaches. In 
a learning-by-doing approach, students are enabled to construct tacit knowledge about creativity, critical thinking, collaboration and communication by themselves through reflection [6]. Constructivism is operationalized in design curricula by project-based learning [4], [6], which has been defined as a student-centred pedagogy in which students construct knowledge while working on ill-defined projects [7]. It has been argued that this enables educators to stimulate active learning as facilitators. In addition to acquiring tacit soft skills and design knowledge, project-based education has been argued to make students take ownership of their learning [8]. This resonates with Schön [15], who states that the essence of design ability is the understanding to make intelligent decisions about design actions through reflection. Reflection, thus, allows students to develop reasoning strategies [8], which may guide them in the iterative development of the project process. These reflecting activities to steer the learning process can be defined as regulation [6], [9]. As the usefulness of regulating skills for designers becomes clear, it raises questions related to how to teach or how to support regulation during project-based learning activities. This paper investigates the effect of the implementation of a group awareness (GA) tool on how students can regulate their own learning in collaborative projects.

\section{REGULATION IN DESIGN EDUCATION}

\subsection{From individual to group and class-level learning}

As previously stated, $21^{\text {st }}$ Century skills may not only be acquired by individual learning, but also through the development of collaborative skills. This is explicitly noted in contemporary discourse that argues for a shift towards multidisciplinary teams [2], [10], [11]. In other words, it is important that individuals in a group learn so that the group can learn. However, as Dillenbourg claims, collaborative learning does not only occur on a group-level, but in order to be meaningful, it should also involve individual and class learning [9]. This is to ensure that project-based collaboration can create a shared understanding through student interactions, commitments to a shared goal and problem solving [12]. Through linking this back to the previously described need for constructing knowledge through reflection in project-based education, it becomes clear that students not only need to be prompted to reflect on a group-level but also on an individual- and class-level.

\subsection{From product-evaluation to product- and process-evaluation}

As regulation on different levels is presented to be a key enabler of learning in project-based learning, it raises the question of evaluation. It is evident that an evaluation of solely the learning product is insufficient. Learners need to reflect during the learning process, resulting in the implementation of process-evaluation. In most higher education courses, students are evaluated at the end through a product-evaluation of the result of their learning. In contrast to product-evaluation, process-evaluation does not evaluate the result but intermediate outcomes. The shift to including process-evaluation is supported by renowned discourse on design thinking and problem solving that states most learning projects in design are complex and ill-defined, referred to as 'wicked' design problems [13]. Wicked problems have no clear definition. So, the designer can only attempt for a solution [14] because these kinds of problems have several acceptable resolutions. The designer chooses the one that corresponds most with the stakeholders' wishes and demands. This iterative process of improvement of designs puts the emphasis on the design process. Elaborating on this, it becomes clear that a shift is needed to extend summative evaluation (i.e. one which takes place at the end of the learning process, evaluating the product) with formative evaluation (i.e. one that occurs during the learning process, evaluating the process). Through formative evaluation students may be prompted to reflect on the process and continue to iterate on their design. These prompts are important as it has been argued that the effectiveness of project-based learning activities has been linked to the opportunity to meaningfully reflect on the experiences and choices made during these activities. Therefore, this study includes both product- and process-evaluation.

This pilot study conducts an intervention in an engineering design course that addresses the theoretical findings. The intervention includes group learning reflection prompts on an individual-, group- and class-level which are related to both product- and process-evaluation. This relates to the last theoretical implementation, namely enhancing the process by not only conducting a summative evaluation but also a formative evaluation. More specifically, this study analyses whether the intervention prompted students to meaningfully reflect on and regulate their collaborative (problem solving) process. 


\section{METHOD}

\subsection{Participants}

All participants $(\mathrm{N}=33)$ of this study are enrolled in the industrial design engineering academic bachelor programme at Ghent University. The study was conducted during a design methodology course within this programme, over the first semester of the academic year 2019-2020.

\subsection{Study set-up}

It has been argued that reflection prompts (i.e. tasks that stimulate reflection) in project-based design courses should enhance students' regulation both on the project content and on the collaboration process [4]. Rummel argues this can be achieved through proactively steering students, particularly by making students aware of the level of collaboration in their project [16]. This study examines whether the implementation of such prompts can have a positive impact on the iterative aspect of the design process, and on the cognitive outcomes (i.e. conceptual understanding of course content) and affective outcomes (i.e. teamwork dynamics). Figure 1 shows the intervention on a timeline divided by the levels of group learning.

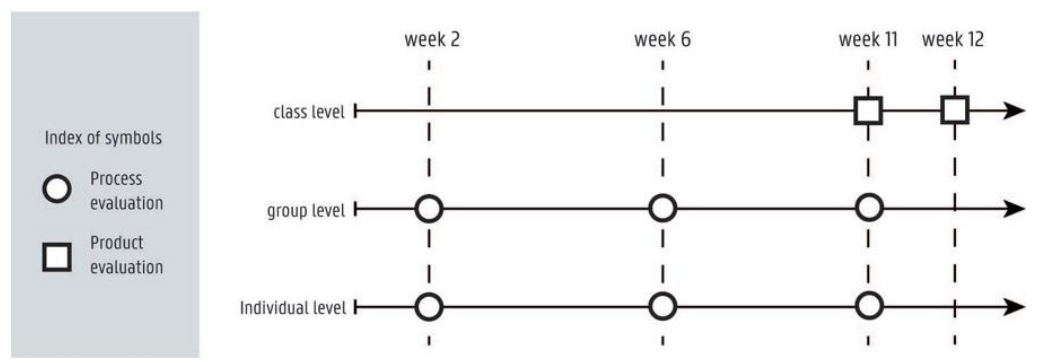

Figure 1. Timeline of the study intervention

The design of this study builds on previous research in the field of peer critique in a design studio environment [17], [18]. Along with a design-based research approach, this study utilizes tools developed in Phielix's previous research [18]. Phielix evaluated the group dynamics during a collaborative learning process. The approach has been described as "a research method for investigating innovative learning environments in a theoretically driven and empirical way, without controlling variables of interest to the degree that is necessary in laboratory studies of learning" [19]. Since this study is situated within an engineering design course setting, it did not seem ethical to divide the class in an experimental and control group to control all the necessary parameters. Therefore, the design-based research approach has been selected as the most relevant one. During the first week of class, participants were informed that the class will involve regulatory reflection prompts. The following week (class week 2 of 12 in total), students filled out a peer critique online survey related to the project process, both on group- and individual-level. In the final weeks (week 11 and 12) the entire class participated in giving feedback during group presentation sessions. These critiques are visualised by the square symbols (Figure 1).

\subsubsection{Individual-level}

The individual critique assessed 5 key parameters (as adapted from Phielix's paper [18]) that concern the process of individual input into group learning, i.e. influence, friendliness, cooperativeness, reliability, productivity. To objectify the results, students were informed of the definition related to each parameter. In the survey (Figure 2), students were asked to score themselves and their team members on these parameters from 0 (very poor) to 4 (very good). Afterwards students were informed of these results through a visualization dashboard, these results were communicated anonymously. Figure 2 shows an example of the survey questions (Figure 2a) and dashboard displays (Figure $2 b$ and $2 c$ ) related to the individual critique survey. The dashboard informs students about the current state of collaborative learning, and then students were asked to reflect on possible behavioural changes (i.e. intentions and resolutions for future behaviour) or remarkable outcomes (i.e. outcomes students do not agree with or find surprising) of the display. Display 1, Figure $2 b$, shows the intermediate results from the first peer critique survey. Each group member is visualised through a different coloured line on the spider diagram. The exact same survey was repeated in class week 6 and 11. Display 2, Figure 2c, illustrates the change in intermediate results. 


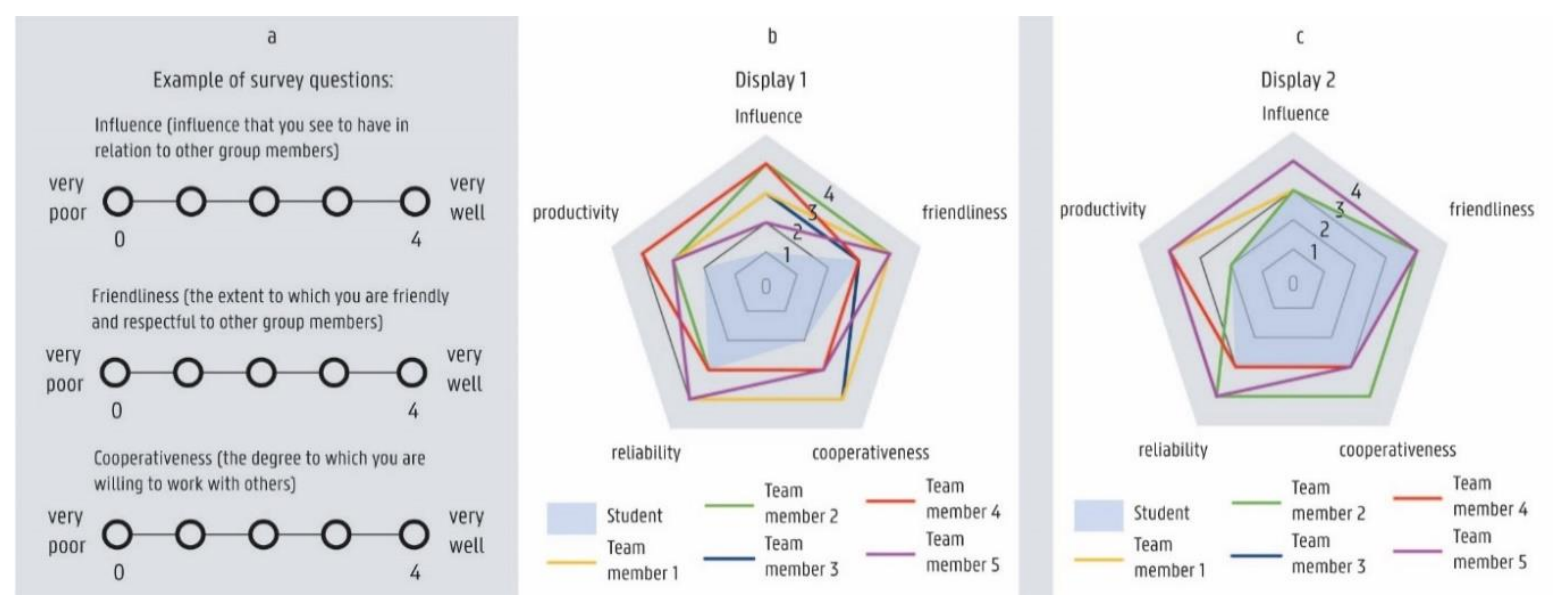

Figure 2. Visualization dashboard individual critique

\subsubsection{Group-level}

The group critique session also assessed 5 key parameters, adapted from and in addition to Phielix's paper [18], which were matched with the project requirements [18]. Like the process-evaluation on an individual-level, these parameters on group-level were also accompanied by a definition to ensure understanding of all group members. The 5 parameters evaluated are team development, group satisfaction, level of group conflict, collaborative problem solving and confidence in group dynamics. After the survey (Figure 3a), every group was informed via another visualization dashboard (Figure 3b and $3 \mathrm{c}$ ) about the results. In week 6 , students were expected to take part in a mandatory group discussion, where they needed to use the results of the group dynamics evaluation as a common ground to address group conflicts. To structure the conversation, students were equipped with a script they could follow. The script consisted of different phases. First the students were asked to create a common ground for the conversation. This meant they had to state issues, remarks and group challenges. Afterwards the script guided them to discuss the design decisions made. To look for a solution they needed to talk about new perspectives and come to a shared agreement for future collaboration.
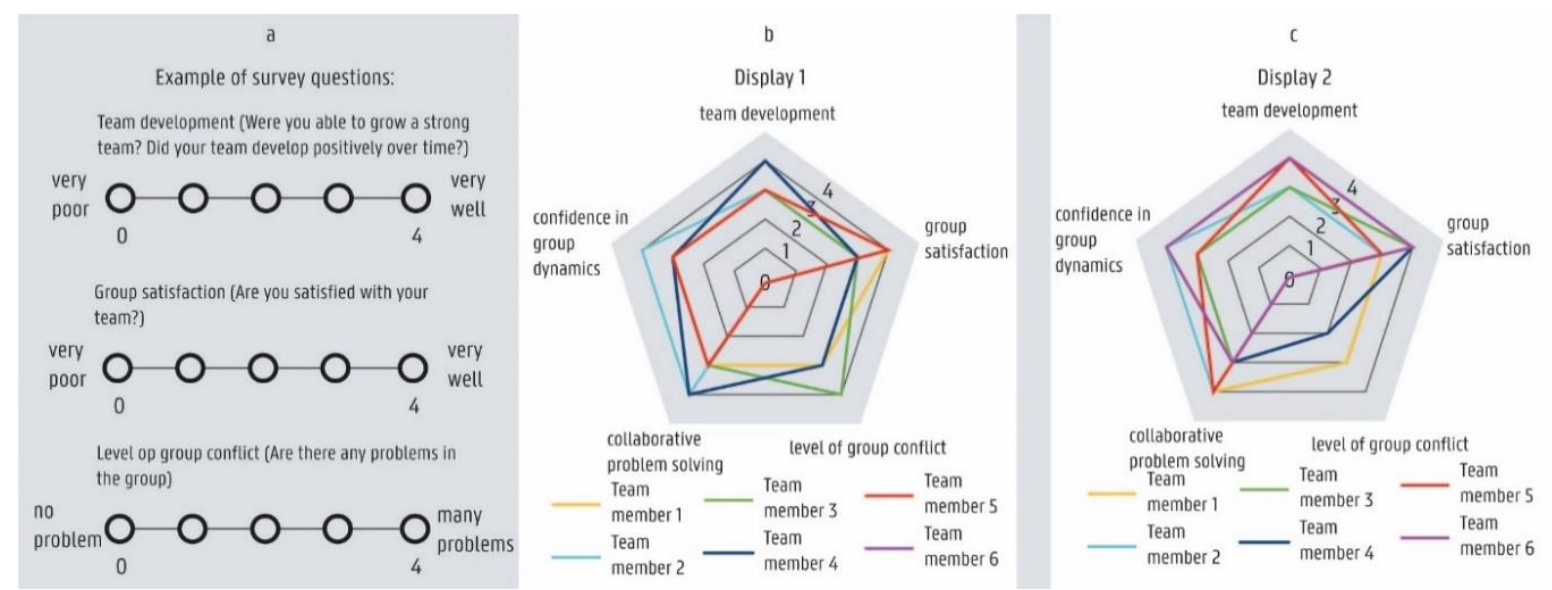

Figure 3. Visualization dashboard group critique

Lastly, in week 11, students did not only participate in process-evaluation but also in product-evaluation. Moreover, as mentioned earlier, it is important that students can meaningfully reflect to learn within a project-based course. Therefore, the product-evaluation did not only entail a summative evaluation in week 12, but also included peer assessment and feedback as formative assessment in week 11 . To be specific, in week 11, students had to present their group work to the educators and their fellow students, enabling regulation on a class-level. During the presentations, other students were encouraged to comment online, using an online collaborative board (Padlet) on the presentations, providing each group with feedback on the presented work. This feedback could then be used to reflect upon, so that students could apply it to their final presentations in week 12. Additionally, after the course finished, students were asked to fill in a survey to reflect on the intervention as a whole and comment on their experiences. 


\section{RESULTS}

During the intervention, students were systematically asked to reflect on the dashboard results. This section presents these results. In relation to the dashboards, students noticed that it was interesting to see how each team member has a different perception of an individual's characteristics. They also found it stimulating to see how, over time, these perceptions changed. Students also noted that the visualisation of the results (Figure 2 and 3, b and c) often encouraged them to change their behaviour by highlighting certain shortcomings. Students considered the way this information was communicated to be valuable. In addition, after the second peer critique survey, some students wanted to fill out the tool again (i.e. fill out the survey and obtain the dashboard results). The reason for this was a conflict in the group and the students involved wanted to use the tool as an objective way to address the situation. In contrast to these positive findings, some students argued that the tool caused them little or no change in their behaviour in the group as there was no problem to address. Moreover, a few students argued that even though they wanted to, the scoring with numbers did not give them enough information to be able to adjust their behaviour accordingly. When asked to share their thoughts in the mandatory group discussion in week 6 , students indicated that the use of the script certainly assisted them in organizing the conversation. However, they argued that it took some effort to focus on the conversation using the script because some opinions were hard to express. Some of these groups deviated from the script by going deeper into the results of the individual critique for each group member.

During the formative product-evaluation on a class-level, students could give feedback on each other's presentations. In the beginning of this exercise it appeared that many students did not know how to formulate this feedback, creating a chaotic start. As the activity progressed, the feedback given increased quality-wise. Some students indicated that this was because the Padlet (the feedback platform) was open for all participants to access. Through this way students could learn from what fellow classmates noticed and commented. Interestingly, a controversial point this intervention revealed is the issue of anonymity. Some students noted that they would dare to speak out more freely when it is possible to use the Padlet anonymously, while others stated that they like to know who assesses them. For example, a student commented that the assessor would have to try to formulate his feedback empathetically and meaningfully, and that the one to be assessed would be able to ask for additional tips. It was remarkable that towards the end of this activity, students themselves actively questioned the students who had just presented and made suggestions as to how their work could be improved.

\section{DISCUSSION, LIMITATIONS AND FUTURE WORK}

By conducting this intervention study, some of the opportunities and shortcomings of group awareness (GA) tools that prompt regulation in a higher education context can be deducted. It was found that students were able to meaningfully reflect on their process both on content and collaboration on individual- and group-level? One of the most interesting comments students made was that they wanted to use the GA tool on their own to objectively address a conflict situation in their team. This indicates an opportunity for future developments so that the tool may be used whenever a team finds it necessary to do so. In addition, students found the visualisation of group dynamics and individual performance useful as a basis to initiate possible behavioural changes or to start a conversation on a meta-level.

However, there are some limitations that should be taken into consideration. The study was conducted within a single course setting, and so this embeddedness might be a limitation as it was only possible to study one class group. Therefore, future research on this tool in multiple-year levels and class groups is necessary. In addition to these limitations, students indicated issues and opportunities for tool expansion. Some students found it hard to use the tool to articulate possible behavioural changes as they lacked information to do so. Therefore, it might be suggested to expand the tool by providing text boxes where teammates could enter constructive feedback. Also, the script should be revised and further developed. Some teams found it hard to use the script to express their opinions. This suggests that the script obstructed an informal conversation, which is known in literature as "over-scripting" [9]. And yet, many participants stated they deviated from the script, adapting the conversation to their own needs. This indicates the conversation was more meaningful than the use of the script itself. The group conversation helped students to identify what went wrong in the group and to create action plans to improve these challenging points. In conclusion, the GA tool offered a lot of benefits to students' group dynamics and learning during this problem-based course. Alas, this is one single method and thus it should be considered in parallel with other successful methods that already exist in pedagogical practice. The authors, who are from the field of engineering design \& education, hope that through presenting this 
research they can inspire other educators and institutions to look for innovative methods that support student's learning and training of $21{ }^{\text {st }}$ Century skills in project-based design engineering courses. Lastly, the authors of this paper would like to thank all students of the design methodology course (academic year of 2019-2020) for their participation in this study.

\section{REFERENCES}

[1] Norman, D.A. "When You Come to a Fork in the Road, Take It: The Future of Design*," She Ji, vol. 2, no. 4, pp. 343-348, 2016.

[2] Justice, L. "The Future of Design Education," Design management review, vol. 30, no. 1, pp. 3337, 2019.

[3] PwC, Curriculum Guidelines for Key Enabling Technologies (KETs) and Advanced Manufacturing Technologies (AMT), January, 2019.

[4] Howe, S. and Goldberg, J "Engineering capstone design education: current practices, emerging trends, and successful strategies," Design education today, pp. 115-148, 2019

[5] Schneorson, D., Persov, E. and Bigger, R., "Designing Your Future - $21^{\text {st }}$ Century Skill-Set for Industrial Designers: The case study of Israel Design Field," The Design Journal, vol. 22, pp. 243-259, 2019.

[6] Morgan, T. "Enabling meaningful reflection within project-based-learning in engineering design education," in Design education today, pp. 61-90, 2019

[7] Stefanou, C., Stolk, J.D., Prince, M., Chen, J.C. and Lord, S.M. "Self-regulation and autonomy in problem- and project-based learning environments," Active Learning in Higher Education, vol. 14, no. 2, pp. 109-122, 2013.

[8] Hmelo-silver, C.E. "Problem-Based Learning: What and How Do Students Learn? JSTOR," vol. 16, no. 3, pp. 235-266, 2004.

[9] Dillenbourg, P. Collaborative Learning: Cognitive and Computational Approaches (Advances in Learning and Instruction), 2nd editio. Emerald Group Publishing Limited, 1999.

[10] Kiernan, L. Ledwith, A. and Lynch,R. "How design education can support collaboration in teams," Proceedings of the 19th International Conference on Engineering and Product Design Education, pp. 14-19, 2017.

[11] Baygin, M., Yetis,H., Karakose, M. and Akin, E., "An effect analysis of industry 4.0 to higher education," 15th International Conference on Information Technology Based Higher Education and Training, pp. 1-4, 2016.

[12] Järvelä et al., S. "Enhancing socially shared regulation in collaborative learning groups: designing for CSCL regulation tools," Educational Technology Research and Development, vol. 63, no. 1, pp. 125-142, 2014.

[13] Buchanan, R. "Wicked Problems in Design Thinking," Design Issues, vol. 8, no. 2, pp. 5-21, 1992.

[14] Gudur, R.R."Challenges in teaching design thinking skills to novice design students," Proceedings of the 18th International Conference on Engineering and Product Design Education, no. September, pp. 140-145, 2016.

[15] Schön, D. The Reflective Practitioner. New York, 1983.

[16] Rummel, N. "Keynote presentation: Thinking Tomorrow's Computer-Supported Collaborative Learning: Challenges and Opportunities," 2019. [Online]. Available: https://www.youtube.com/watch?v=RRoemorpxhs.

[17] Wilder, D.and Gray, C.M., "Enculturating Peer and Instructor Critique in a Transdisciplinary Technology Studio Environment," Art design and communication in higher education no. December, p. 2, 2013.

[18] Phielix, C., Prins, F.J. and Kirschner P.A., "Awareness of group performance in a CSCLenvironment: Effects of peer feedback and reflection," Computers in Human Behaviour, vol. 26, no. 2, pp. 151-161, 2010.

[19] Anderson, T and Shattuck, J., "Design-based research: A decade of progress in education research?," Educational Researcher, vol. 41, no. 1, pp. 16-25, 2012. 